MEMÓRIA

\title{
Desenvolvimento da Genética em São Paulo nos Últimos Vinte Anos
}

\section{Apresentação}

Joaquim A. Machado

Engenheiro Agrônomo - USP

Em 1954, Dr. Alcides Carvalho, geneticista de café, escreveu um interessante texto no qual relata as atividades em Genética e Melhoramento no Estado de São Paulo, nos vinte anos anteriores. Várias lembranças me vêm a mente sobre o Dr. Alcides e sobre a antiga Seção de Genética do Instituto Agronômico de Campinas. Duas delas merecem comentários iniciais.

Durante visitas como estudante e estagiário da ESALQ, ou durante eventos científicos no IAC, me agradava passar pela sala de trabalho do Dr. Alcides. Para o melhorista de plantas, aquela sala representava, se não um templo, quem sabe uma igreja leiga. As atividades e os recursos materiais demandados pelo trabalho de melhoramento, em muito se assemelham àqueles da Antropologia e da Arqueologia. Portanto, nenhuma novidade em se perceber, à medida que passa o tempo, que de fato o Melhoramento Genético pertence ao campo da Antropologia, e vive de recursos de pesquisa similares àqueles da Arqueologia.

A sala de trabalho do Dr. Alcides era um festival para os olhos e a mente, com seus armários, arquivos, grandes mesas de madeira com infindáveis pastas, fichas de registro, cadernos de campo (ainda não estávamos em tempos de planilhas virtuais) anotados a lápis, amostras de sementes, fotos e muitos livros. Que riqueza. E ligando os pontos, a figura gentil de Dr. Alcides, dialogando e ensinando. 
A segunda e recorrente lembrança advém de uma visita que fiz ao IAC, como professor assistente do Departamento de Genética da Escola Superior de Agricultura Luiz de Queiroz, em 1983. Em debate no campus, naquele ano, o destino de algumas "áreas ociosas" da ESALQ, sob pressão de interesses imobiliários e mesmo de outras instituições públicas. Alunos e professores se mobilizavam então para obter uma difícil solução que atendesse a instalação de novas atividades de pesquisa e desenvolvimento, em face de recursos sempre limitados.

Há muito eu imaginava que a ESALQ poderia ter uma área específica denominada "Parque de Germoplasma", que pudesse abrigar coleções significativas da Botânica Econômica. Iniciativa que atualmente o próprio IAC busca implementar em sua Fazenda Santa Elisa (Centro Experimental), em Campinas, bem como em suas estações experimentais distribuídas pelo Estado de São Paulo. Algumas poucas já se foram, fruto de falta de visão sobre a importância econômica e sociocultural da conservação de recursos genéticos, ou frente à visão contemporânea sobre a maior utilidade de tais áreas para o agronegócio.

A primeira pessoa que busquei para implementar esse Projeto na ESALQ foi o Prof. Dr. Flávio Tavares, do Departamento de Genética, que imediatamente apoiou a proposta, visionário que sempre foi e continua sendo. A segunda pessoa, foi exatamente Dr. Alcides Carvalho, em sua sala no IAC. Minha mente viajava então pelas imponentes e tradicionais Estações Experimentais instaladas nas regiões tropicais do mundo, com suas coleções de plantas, seus antropólogos-arqueólogos-geneticistas, Companhias das Índias e especiarias, coletas de plantas em regiōes distantes e profundos estudos taxonômicos, etnobotânicos e genéticos, visitas a museus para troca de informação e material, bem como aulas em universidades sobre as Origens da Agricultura e Agricultura Internacional.

Dr. Alcides tomou de seu tempo apenas alguns minutos, para ler minha mente e me ouvir, e logo em seguida abriu um de seus arquivos e pegou uma folha de papel onde já estava esboçado a lápis o croquis de uma coleção de variedades de café, bem como de espécies e gêneros relacionados, num caminhamento que possibilitava viajar pela história do café, da genética do café, e do melhoramento do café. Sem mais demora tomou seu chapéu, e caminhou comigo até a coleção de cafés do IAC, onde pessoalmente indicou aos seus assistentes quais as variedades e quantas mudas deveriam ser oferecidas à ESALQ. 
Obviamente, aquela inesquecível visita terminou na sempre agradável conversa informal com Dr. Alcides, ao redor do inigualável cafezinho da Seção de Genética do IAC.

Uma valente Kombi se encarregou de levar a preciosa coleção até a ESALQ. Tempos e eventos se passaram, e assim como as células vivas dependem de contexto e sinalização social para permanecerem, aquela coleção de contexto dependia. Não tendo acontecido o contexto adequado, a coleção se perdeu. Lições para a ESALQ de hoje, e para o IAC de hoje, em tempos de novos contratos sociais de acesso a recursos genéticos.

O texto de Alcides Carvalho demonstra que a ciência e a personalidade do homem, a Genética e o geneticista, ambos modernos e contemporâneos, construíram patamares sólidos com similitude lógica. IAC e Alcides Carvalho. Há portanto que buscar evidências em favor dessa proposição. E essa caminhada pode começar pelas seçôes antigas das bibliotecas do IAC e da ESALQ. Nelas se ouve o balbucio dos mestres: conheça sua terra, conheça sua gente, e suas demandas socioeconômicas, e aplique com excelência a Ciência de mais alto nível. IAC e ESALQ em tempos de redescoberta da Genética: uma recomendável harmonização entre a Ciência e a aplicação da mesma à resolução de problemas locais. Sem abandono de uma causa pela outra. Apenas a excelência em qualquer caso. Essa é a narrativa de Alcides Carvalho, em 1954.

Dr. Alcides abre o texto com uma límpida visão sobre o impacto dos modernos procedimentos laboratoriais, de campo e estatísticos, desenvolvidos pela Genética de então, descrevendo como essas descobertas alistavam muitos novos pesquisadores, não apenas da área biológica, como também da química, da física e da matemática. Menciona também o impacto dos novos conhecimentos e tecnologias no melhoramento de espécies de plantas e animais domésticos. E não se esquece de privilegiar os numerosos estudos sobre Evolução.

Cabe perguntar: é esse um texto de 1954 ou de 50 anos mais tarde? Feita a pergunta, estabelece-se uma interessante simetria na escala temporal. Cinqüenta anos antes do texto em questão, a redescoberta das Leis de Mendel. Cinqüienta anos depois do texto, acontece um novo ciclo de desenvolvimento de tecnologias disruptivas em Genética, em relação ao qual os comentários iniciais de Dr. Alcides são absolutamente pertinentes. E o mais interessante, é o reconhecimento do autor sobre a ligação indissolúvel entre ciência básica e 
aplicação científica, bem como sobre o caráter politécnico da Genética. Genética e Genômica, Genômica e Ciência da Informação, Genética Molecular e Química Combinatória. O cenário contemporâneo atesta a modernidade de Alcides Carvalho.

Outro aspecto que ressalta o caráter documental do texto do Dr. Alcides. Embora não mencione diretamente, 25 de abril de 1953 é a data de publicação em Nature, da descoberta de Watson, Crick e outros. Publicação que começa com a simplicidade das descobertas magnas, imediatamente contempladas com a perenidade encontrada na abertura de textos literários clássicos de S. Fitzgerald e G. Greene: "We wish to suggest a structure for the salt of deoxyribose nucleic acid (D.N.A.). This structure has novel features which are of considerable biological interest."

Portanto, o texto do Dr. Alcides situa-se exatamente no centro da escala temporal estabelecida pela história da Ciência, como se fosse uma pausa para contemplar os primeiros 50 anos; como se fosse agora um caminhar da popa até a proa, mirando os próximos 50 anos, a partir do encanto da descoberta de um novo território científico a explorar, com seus mistérios e suas riquezas sem fim.

Ainda em busca de simetrias, aprende-se no texto do Dr. Alcides, que o IAC inicia estudos em Genética em 1927, instalando-se em 1935 a cadeira de Genética na ESALQ. Mais um marco interessante na escala temporal. Algo como 25 a 30 anos depois da redescoberta das Leis de Mendel, estabelece-se no Brasil dois centros de excelência em Genética básica e aplicada.

Muito pode ser encontrado no texto, tal como o grande número de espécies às quais foram dedicados estudos, desde as clássicas espécies utilizadas em Genética básica, até espécies de importância econômica para o País, incorporando-se também espécies de potencial interessante e de pouco conhecimento estabelecido até então.

Mais que isso, salta aos olhos o esforço de integração entre e dentro de grupos de pesquisa, sempre em busca da excelência e da atualização de conhecimento. Estimula a imaginação ler que "em 1948, a Reitoria da Universidade de São Paulo, a Fundação Rockefeller e a Carnegie Institution de Washington possibilitaram a reunião, no laboratório de André Dreyfus, de 11 investigadores de várias universidades para trabalhar por 12 meses com as populações de drosófilas brasileiras". Entre esses, Th. Dobzhansky da Universidade de Columbia. Imagi- 
ne-se também o espírito de aventura e de descoberta, uma vez que o grupo trabalhou com populações de drosófilas dos estados de São Paulo, Pará, Goiás, Bahia, Maranhão, Rio Grande do Sul e Rio de Janeiro, além dos territórios do Iguaçu, do Acre, do Guaporé e do Rio Branco, sem faltar também amostras vindas da Argentina, Uruguai e Trinidad. Os resultados foram publicados pelo Departamento de Biologia Geral da Faculdade de Filosofia de São Paulo.

Dr. Alcides menciona também, entre muitos outros estudos, aquele realizado por C. Pavan e M. Brauer, com cromossomos politênicos de células de vários tecidos em Rhynchosciara angelae. Estudos de elegância e ineditismo tais que permanecem como referência científica maior. E comenta os estudos aplicados de Krug, Viegas e Paolieri com milho (existe uma revista Bragantia, publicada em novembro de 1943, a qual sumariza dez anos de trabalho com milho híbrido, além de documentar intercâmbio de linhagens com diversas instituições, entre essas a Escola Superior de Agricultura de Viçosa em Minas Gerais; intercâmbio que originou um padrão de sementes de milho típico do Brasil, bem como uma das maiores empresas privadas nacionais, produtora de sementes desse cereal).

Finalmente o café, com o qual tradicionalmente se abre e se encerra um agradável período de recordação. Em seu texto, Dr. Alcides se inclui em memorável grupo de geneticistas e melhoristas de café do IAC, explicando que esse grupo "tem contribuído para elucidar problemas relativos à taxonomia, genética e melhoramento do café". Com modéstia e simplicidade, avança na narrativa de que se trabalhou na análise de produção de mais de 60.000 cafeeiros e das características de suas sementes por todo o Estado de São Paulo, as quais, depois de multiplicadas, totalizaram cerca de 30 milhôes de covas de cafeeiros, todos derivados de linhagens selecionadas no Instituto Agronômico de Campinas.

Não mais temos conosco o Dr. Alcides Carvalho. Mas sua memória, seus feitos, e a sua dedicação à Genética podem ser recuperados pela leitura de seu excelente e agradável texto, na companhia de um bom cafezinho. Não são essas, grandes qualidades da nossa terra e da nossa gente? 
Memória 


\title{
Desenvolvimento da Genética em São Paulo nos Últimos Vinte Anos
}

\author{
Alcides Carvalho \\ Instituto Agronômico - Campinas
}

Não há revista científica da atualidade, de caráter biológico, que não traga, em qualquer de suas ediçôes, artigos referentes aos vários ramos da mais nova das ciências biológicas, isto é, da genética. É que hoje em dia as pesquisas relativas à herança dos fatores genéticos, quer nos indivíduos ou nas populações, à ação desses fatores ou à sua própria constituição e modo de multiplicação, empolgam grande número de investigadores dedicados aos vários ramos da biologia, da microbiologia, da química, da física, da matemática, etc. Além disso, há os numerosos trabalhos sobre a evolução e os que se referem à aplicação dos princípios da genética no melhoramento das espécies de plantas e dos animais domésticos.

Embora sejam os mesmos os princípios mendelianos, quer se trate de sua aplicação aos microrganismos ou mesmo à espécie humana, a genética vem evoluindo com tal rapidez que já se encontram no cenário mundial especialistas em genética de população, em genética fisiológica, citogenética, imunogenética, genética humana, genética dos microrganismos, os que se dedicam ao estudo dos agentes físicos e químicos provocadores das mudanças hereditárias e os que voltam suas vistas para o estudo da própria constituição química dos fatores genéticos e para o estudo dos fatores localizados no citoplasma.

Com a especialização dos técnicos tem igualmente surgido a especialização dos laboratórios. Alguns deles passaram a trabalhar exclusivamente com espécies de Drosophila, determinando o modo de herança de seus característicos, a localização dos fatores genéticos nos cromossomos, as suas complexas interações, os vários efeitos das combinaçóes e posição dos gens nos cromossomos e seu valor evolutivo. Outros elegeram o milho para objeto de estudos, tornandoo uma das plantas mais bem conhecidas do ponto de vista genético e daí resultando o famoso milho híbrido, a estupenda realidade de tão grande valor 
prático e que todos admiram. Alguns centros mais especializados passaram a estudar os microorganismos, tanto fungos como bactérias, dedicando imensos esforços para desvendar as particularidades das reações bioquímicas que neles se operam durante a elaboração de várias substâncias químicas, auxiliados pelas mutações que ocorrem nesses microorganismos. A intensa produção de antibióticos salvadores de milhares de preciosas vidas humanas atesta a importância do desenvolvimento das pesquisas genéticas e das mutações nos microrganismos. Outros estabelecimentos científicos, igualmente superespecializados, investigam a herança dos característicos nos bacteriófagos, tipos de vírus que atacam as bactérias e cujo estudo requer grande refinamento de técnica.

Com horizontes assim tão amplos seria de se esperar progresso constante da genética em todos os países. Realmente isso vem ocorrendo, porém em maior escala, principalmente nos Estados Unidos, na Inglaterra, no Japão, na Dinamarca, na Suécia e em alguns outros países.

\section{As pesquisas genéticas na ESALQ}

No Brasil, tanto o ensino como as pesquisas da genética vêm tomando notável incremento nestes últimos anos. É de se presumir que entre nós essas pesquisas sejam cada vez mais ampliadas a fim de se obterem dados básicos para o desenvolvimento de outros ramos da biologia. No Estado de São Paulo, como será indicado neste apanhado geral, os trabalhos sobre genética vêm sendo efetuados principalmente em Piracicaba, São Paulo e Campinas, sendo que foi nesta cidade, no Instituto Agronômico, que se criou, em 1927, a primeira seção especializada nesse ramos da biologia.

Até o momento a única Faculdade da Universidade de São Paulo que possui uma seção especialmente dedicada ao ensino e pesquisa genética é a Escola Superior de Agricultura "Luís de Queiroz", de Piracicaba, embora na cadeira de Biologia Geral da Faculdade de Filosofia de São Paulo também seja dado um curso de genética. Mesmo antes de se criar esta seção, em Piracicaba, o ensino das bases da genética era aí ministrado pelos professores Carlos Teixeira Mendes, Otávio Domingues, S. de Toledo Piza, N. Athanassof e A. Paravacini Torres, o que torna Piracicaba o centro mais antigo de ensino de genética em São Paulo.

Carlos T. Mendes, logo após seu ingresso na Escola, começou a transmitir 
aos seus alunos, com seu peculiar entusiasmo, as teorias evolutivas, chamando especial atenção aos fundamentos da genética moderna, e Otávio Domingues foi, também, um dos mais entusiastas pioneiros do ensino e divulgação dos princípios da genética entre nós, publicando numerosos artigos, escrevendo livros sobre a genética aplicada ao melhoramento dos animais e contribuindo, com os demais professores, para que se formasse uma mentalidade propícia para a instalação, em 1935, da cadeira de genética, logo após a passagem da "Luís de Queiroz” para a Universidade de São Paulo. Para reger essa cadeira foi contratado o geneticista F. G. Brieger. Auxiliado por Edgard Graner e J. T. A. Gurgel, conseguiu Brieger instalar, em Piracicaba, um dos mais completos laboratórios destinados a pesquisas sobre genética e citologia no País. Os cursos de genética, citologia e estatística, lecionados na "Luís de Queiroz", passaram a atrair a preferência de muitos estudantes, tanto da própria Escola como de outros estados da União e de outros países do continente, e Brieger e seus assistentes têm-se mostrado incansáveis na divulgação dessas matérias.

Observando que a origem do milho é um dos mais fascinantes problemas relativos a esse cereal, Brieger começou a estudá-lo, tomando como hipótese as regiōes de baixa altitude da Bolívia até a chapada dos Parecis no Brasil como provável região de origem do milho. A partir dessa zona esse cereal deve ter se difundido por vários caminhos radiais a outras regióes do continente americano. Os característicos das raças indígenas de milho ainda existentes são, segundo este autor, indicadores destes caminhos. As duas regiões que outras hipóteses dão como provável origem do milho, isto é, a região andina da Bolívia e Peru e a região mexicana e guatemalteca figuram neste esquema como centros de diversificação secundária. O milho, segundo os trabalhos de Brieger, deve ter se originado pelo cruzamento de um tipo primitivo tunicata com uma espécie de Tripsacum sul-americano. Observações referentes à origem e evolução das espécies de orquídeas vêm, também, ultimamente, sendo realizadas. Embora tenha efetuado pesquisas com o milho, fumo, citrus e plantas ornamentais, Brieger vem realizando vários outros estudos teóricos sobre genética de população a fim de, principalmente, explicar o fenômeno da heterose, encontrado em várias plantas, inclusive no milho.

Visando impedir o desaparecimento de variedades comuns de milho, principalmente das regiōes onde ocorre sua maior diversidade genética como 
na Bolívia, Paraguai, Peru, Brasil, etc., organizou-se em Piracicaba, sob os auspícios da Academia Nacional de Ciências de Washington, um dos centros de preservação do germoplasma do milho, enquanto outros foram instalados na Colômbia e no México. Assim, centenas de variedades de milho que hoje não oferecem vantagens agronômicas, mas que amanhã poderão ser de utilidade, não mais se perderão. E. Paterniani, desse laboratório, vem realizando estudos para que essas variedades possam ser mantidas sem grande perda de vigor e coligindo dados para a descrição das raças de milho dos índios Caingang.

E. A. Graner, atual catedrático da cadeira de Agricultura Especial da "Luís de Queiroz", tem também se dedicado ao estudo do milho, localizando em seus cromossomos alguns dos alelos encontrados no milho do Brasil e que afetam principalmente a cor do endosperma da semente. Com G. Addison mostrou que a espécie de Tripsacum do Paraguai, provável ancestral do milho, possui cromossomos desprovidos de nós, tal como diversas variedades de milho do continente sul-americano já analisadas. Reconhecendo o interesse que a mandioca tem na alimentação humana, realizou Graner os primeiros estudos de genética dessa espécie e obteve formas poliplóides, pelo uso da colchicina. O mamoeiro também foi objeto de investigações, procurando esclarecer o mecanismo da determinação do sexo de suas flores. Observações sobre a herança de alguns característicos das aves, principalmente daqueles relacionados com a coloração de ovos e ausência de penas no pescoço das galinhas foi realizado por Graner e A. P. Torres. O compêndio sobre Genética publicado por E. Graner tem-se revelado bastante útil na divulgação dos princípios de genética entre nós.

J. T. A. Gurgel, também do laboratório de Genética, dedicou vários anos à execução de análises genéticas dos característicos de outra espécie de importância econômica, isto é, a mamoneira, procurando esclarecer as combinações de pigmentos que ocorrem nessa planta, resultantes de interações complexas de vários alelos, e a herança de diversos outros característicos. Vem atualmente se dedicando ao estudo do feijão, contando com elevado número de espécies em sua coleção, as quais vêm sendo analisadas do ponto de vista citológico, genético e evolutivo. Os mutantes encontrados no milho sul-americano estão também sendo estudados, procurando, pelo uso de "testers" apropriados, verificar em quais cromossomos se acham localizados. Outro grupo de plantas 
em investigação, em colaboração com S. Moreira, do Instituto Agronômico de Campinas, é constituído pelas plantas cítricas, nas quais se procura determinar o grau de poliembrionia de suas espécies. As mirtáceas produtoras de frutos comestíveis, como jabuticabeiras, goiabeiras e outras, vêm sendo analisadas em colaboração com J. Soubihe Sobrinho, do Instituto Agronômico de Campinas. Observações sobre poliembrionia e conteúdo de vitaminas dessas plantas têm sido feitas a alguns anos, do que resultou a constatação de que a cabeludinha é uma das plantas que maior quantidade de vitaminas $C$ possui e que portanto deve entrar no plano de melhoramento dessas mirtáceas.

A agricultura paulista já está familiarizada com as excelentes variedades de repolho, couve-flor, cenoura, alface e várias outras plantas hortícolas que M. Dias vem obtendo pela aplicação de método especial de melhoramento a essas espécies, lançando mão de variedades locais e importadas. As variedades de brócoli e os trabalhos de genética do quiabo e também do mamão se acham a cargo de J. Mitidieri, enquanto N. Kobal e M. Mezzacapa, desse mesmo laboratório, preocupam-se principalmente com o estudo do milho comum, pipoca, milho doce e plantas ornamentais, tais como ervilha-de-cheiro, boca-de-leão, etc.

Trabalhos de outra natureza são realizados por Warwick E. Kerr com as abelhas sem ferrão do grupo das Trigonas e Melíponas. Desenvolvendo técnicas especiais para a criação, pode estudar a constituição genética das castas destas abelhas, e vem atualmente desenvolvendo pesquisas relativas à ecologia e evolução deste grupo de insetos. Um levantamento das principais espécies de plantas melíferas e nectaríferas vem sendo realizado, a fim de melhor estudar os hábitos de alimentação das abelhas em geral, e aumentar a sua produção de mel.

Uma série de estudos de bastante atualidade vem sendo realizada por Salvador de Toledo Piza, catedrático da cadeira de Zoologia, referente à evolução e estrutura de cromossomos, principalmente dos escorpiōes e sobre a função dos cromossomos em geral e também a respeito do papel do citoplasma no desenvolvimento do organismo. A forma toda especial que tomam os cromossomos do escorpião ao se dirigirem aos pólos durante a divisão celular tem sido objeto de intensivos estudos por Piza, a fim de explicar a natureza dos centrômeros desses cromossomos. Cumpre ainda notar que numerosas publicações sobre genética e assuntos correlatos têm sido editadas por Piza, que também se tornou conhecido pelas suas brilhantes conferências científicas. 
Felipe W. Cabral de Vasconcelos, catedrático da cadeira de Horticultura, estudando as formas de citrus de sua coleção, isolou a linhagem de laranja, hoje conhecida por Baianinha de Piracicaba, originada por mutação somática e que vem sendo amplamente cultivada nos novos pomares de São Paulo.

\section{A Faculdade de Filosofia}

Mencionar os trabalhos de Genética que ora se realizam em São Paulo é lembrar o nome inesquecível do Prof. André Dreyfus. Pouco tempo depois de sua transferência do Rio para São Paulo, passou Dreyfus a se interessar pelos estudos da genética e a realizar conferências e cursos sobre Genética e Eugenia, principalmente na Escola de Medicina de São Paulo. Com a criação da Faculdade de Filosofia, Ciências e Letras da Universidade de São Paulo, começou a ministrar aí os cursos de Biologia Geral e de Genética, e realizar pesquisas sobre vários problemas relativos a esses assuntos.

Com seu amplo cabedal científico e facilidade de expressão, com seu contagiante entusiasmo, dedicação e simpatia, soube Dreyfus, prendendo sempre a atenção do auditório, ministrar a muitos os ensinamentos de genética e evolução e organizar uma das mais brilhantes escolas de genética do continente.

Além dos vários trabalhos de natureza geral e sobre a citologia comparada de vermes, e determinação do sexo nos himenópteros e sobre os peixes cegos das cavernas, realizados nesse laboratório, o "grupo Dreyfus", constituído por ele e seus vários assistentes, passou aos problemas da genética de população e evolução. Em 1943 se dedicou a um plano de estudo evolutivo das espécies tropicais de drosófila, material bastante favorável para estas pesquisas. Nesse ano um dos mais ilustres geneticistas da atualidade, o Prof. Th. Dobzhansky, da Universidade de Columbia, de Nova York, esteve em São Paulo e elaborou, neste laboratório, as bases de um extenso plano de pesquisas de genética e ecologia das populações de drosófilas do Brasil, em colaboração com Dreyfus e seus assistentes C. Pavan, A. Brito da Cunha, Newton Freire Maia, Rosina de Barros, Eliza Knapp e outros.

A execução desta série de pesquisas tornou-se possível graças ao inestimável auxílio que a Fundação Rockefeller vem prestando a este laboratório e a todos aqueles que se dedicam ao estudo da genética em São Paulo. 
Primeiramente, deu-se um balanço geral de modo a se conhecer melhor as espécies aqui existentes e também para se poder escolher as de maior interesse para futuros estudos. Amostras de drosófilas começaram a ser coletadas em regiōes localizadas em numerosos pontos do território brasileiro, de norte a sul e de leste a oeste. Assim, logo de início, foram encontradas 27 novas espécies de drosófilas, por Pavan e Dobzhansky. Hoje já se conhecem muitas outras espécies do Brasil, uma das mais ricas regiōes em drosófilas no mundo. Duas delas, isto é, Drosophila willistoni e D. prosaltans foram escolhidas para estudos detalhados. É que há indicações de que a primeira dessas espécies tem tamanho grande de população, enquanto a $D$. prosaltans tem tamanho pequeno de população. Estes dois representantes do grupo das drosófilas brasileiras foram levados para Nova York e lá cruzados com outros indivíduos de constituição genética conhecida, de modo a se tornarem marcados e reconhecíveis os seus cromossomos. Passaram-se cinco anos e as drosófilas com os cromossomos geneticamente marcados voltaram para São Paulo, agora para participar do plano geral do estudo genético de suas populações. Em 1948 a Reitoria da Universidade de São Paulo, a Fundação Rockefeller e a Carnegie Institution de Washington possibilitaram a reunião, no laboratório de Dreyfus, de 11 investigadores de várias universidades para trabalhar por 12 meses com as populaçóes de drosófilas brasileiras. Estes pesquisadores, isto é, N. S. Dobzhansky e Th. Dobzhansky da Universidade de Columbia (N. York), Marta Wedel da Universidade de Buenos Aires, Hans Burla da Universidade de Zurich, Chana Malogowkin e A. G. L. Cavalcanti da Universidade do Brasil, A. R. Cordeiro da Universidade de Porto Alegre, Eliza Knapp, André Dreyfus, Antônio Brito da Cunha, C. Pavan e N. Freire Maia, da Universidade de São Paulo e ainda Boris Spassky também da Universidade de Columbia, passaram a estudar a posição sistemática da $D$. willistoni $\mathrm{e} D$. prosaltans em relação às espécies mais afins, o número de espécies de drosófilas do Brasil com suas freqüências nas várias regiōes climáticas e em meses diferentes do ano, os dados ecológicos relativos à $D$. willistoni, a estrutura citológica das populações de $D$. willistoni e $D$. prosaltans e a estrutura genética das populações destas duas espécies.

No Estado de São Paulo três foram as localidades escolhidas para coletas periódicas de amostras de moscas, a saber: Vila Atlântica, na costa, Mogi das Cruzes e Piraçununga, no planalto. Posteriormente foram analisadas amostras de 
moscas do Pará, Goiás, Bahia, territórios do Iguaçu, do Acre, do Guaporé, do Rio Branco, Maranhão, Paraná, Rio Grande do Sul, Distrito Federal, Rio de Janeiro e também da Bolívia, Argentina, Uruguai e Trinidad, num total de 42 localidades. Milhares de moscas foram e vêm sendo ainda analisadas anualmente e importantes contribuições científicas já foram apresentadas pelo Departamento de Biologia Geral da Faculdade de Filosofia de São Paulo, sobre a variabilidade encontrada nessas moscas.

Assim, Pavan e seus colaboradores, estudando a variabilidade genética das populações brasileiras de D. willistoni, descobriram que mais de um terço dos cromossomos dessa espécie contém mutantes recessivos que são letais ou semiletais quando homozigotos; aproximadamente outro terço dos cromossomos contém gens subvitais que reduzem a viabilidade dos homozigotos. Outros cromossomos tornam os homozigotos estéreis ou modificam sua taxa de desenvolvimento ou causam mudanças estruturais visíveis no corpo da mosca. Os letais encontrados são de vários tipos e Pavan calculou que 500 a 1.000 gens do segundo cromossomo D. willistoni são capazes de mutar produzindo gens letais.

A. R. Cordeiro, atualmente na Universidade de Porto Alegre, mostrou que a maioria dos letais encontrados nas populações de D. willistoni são deletérios, não só quando homozigotos mas também em menor grau, nos heterozigotos. Outros letais são todavia neutros ou mesmo aumentam levemente o vigor dos heterozigotos.

A. Brito da Cunha, com H. Buria e o Prof. Dobzhansky descobriram que as freqüências de inversões cromossômicas nas populações de $D$. willistoni nas regiões de Goiás, Tapajós, Acre e Rio Negro, são muito mais elevadas do que em certas outras populações como as da caatinga da Bahia, do Rio Grande do Sul, da Argentina e de Marajó. Formulou-se uma hipótese para explicar as diferenças entre as populações das várias regiões, admitindo que a variabilidade genética ou o polimorfismo é uma resposta de adaptação das espécies ou das populações à diversidade dos ambientes que essas espécies ou populações dispõem para sua vida. Esta hipótese de tão grande interesse foi confirmada por Brito da Cunha, D. Brncic e F. M. Salzano. O polimorfismo de adaptação pode também ser produzido por gens alelos que conferem aos heterozigotos um valor de adaptação superior ao dos homozigotos. Brito da Cunha encontrou tais genes nas populações brasileiras de D. polymorpha e Newton Freire Maia, 
atualmente professor da Universidade do Paraná, encontrou gens com estas propriedades na espécie $D$. montium.

Outras espécies de Drosophila do Brasil vêm sendo estudadas. Assim Rosina de Barros se dedica ao estudo de D. repleta, enquanto $D$. nebulosa é estudada por C. Pavan, as espécies D. polymorpha, D. cardinoides, D. guaramuru, D. griseolineata, D. bandeirantorum e D. pallidipenis são analisadas por Brito da Cunha, Brncic e Salzano e D. sturtevanti por Eliza Knapp.

Observações referentes à diferença entre três espécies anteriormente classificadas em conjunto como D. bocainensis, foram realizadas pelo Prof. H. L. Carson, da Washington University de St. Louis, quando de sua permanência em São Paulo.

Uma série de novas investigações sobre as preferências nutritivas das drosófilas brasileiras começou a ser efetuada por Brito da Cunha em colaboração com o Prof. Dobzhansky, o que irá ampliar consideravelmente o conhecimento da ecologia das espécies brasileiras de Drosophila.

Recentes trabalhos realizados por Pavan e M. E. Breuer, desse mesmo laboratório, indicaram a semelhança das faixas dos cromossomos politenicos em células de vários tecidos de Rhynchosclara angelae e as mudanças das faixas em bulbos e vice-versa durante o desenvolvimento das larvas.

A importância dos trabalhos que ora se realizam sobre as drosófilas se prende, em parte, à analogia que existe entre as estruturas das populações de drosófilas e a de outras espécies que se reproduzem por fecundação cruzada, tal como a espécie humana.

Uma série de pesquisas básicas referentes às freqüências de casamentos consangüíneos em várias localidades e em épocas diferentes, foram iniciadas por $\mathrm{N}$. Freire Maia, na Faculdade de Filosofia de São Paulo, a fim de verificar a tendência da quebra dos isolados nas populações humanas. Com o aumento da facilidade de comunicação entre as localidades, verificou esse autor diminuição nos casamentos consangüíneos, tal como se tem observado em outros países.

Os trabalhos sobre genética e evolução publicados pelo Departamento de Biologia de São Paulo, nas melhores revistas internacionais especializadas, têm contribuído para o conceito tão elevado em que é hoje tida a Faculdade de Filosofia da Universidade de São Paulo.

Outros pesquisadores dedicados a assuntos médicos e trabalhando no 
Laboratório Paulista de Biologia e na Faculdade de Medicina, vêm estudando com detalhes os grupos sangüíneos das populaçōes brasileiras e determinando a sua constituição genética. Como se sabe, há várias propriedades do sangue de alguns animais, e também do homem, controladas por fatores genéticos e os indivíduos de uma dada população no geral diferem um de outro quanto a estes característicos. Algumas destas propriedades precisam ser consideradas toda vez que se fizer uma transfusão de sangue. Como se trata de um característico não influenciado pelo meio ambiente e como na população humana os casamentos se têm realizado sem o conhecimento do grupo sangüíneo, torna-se possível, pelo estudo dessas propriedades do sangue, tirar informações quanto às diferenças entre populações, locais, de localidades diferentes e também obter informações sobre a origem provável de certas aglomerações humanas. F. Ottensooser, C. da Silva Lacaz, R. Pasqualin, H. C. Ferreira e O. Mellone são alguns dos pesquisadores que têm apresentado interessantes trabalhos sobre as freqüências dos alelos $I^{A}, I^{B}, I, M, N, R H$, etc., nas populações de São Paulo e também na dos índios de certas regiōes do Brasil. As observações da incidência desses vários alelos entre as populações indígenas são de bastante atualidade e devem ser intensificadas antes que os meios mais rápidos de transporte venham a quebrar os isolados que essas populações formam. As pesquisas levadas a efeito sobre os alelos da série Rh revelaram que a população de São Paulo se assemelha à população de Nova York não apenas quanto aos alelos, como também quanto à sua freqüência. $\mathrm{O}$ interesse que desperta o estudo do fator Rh se prende ao fato de uma certa combinação genética de mãe e filho ser de certo modo incompatível, resultando, com relativa freqüência, a morte do filho ou a ocorrência da moléstia eritroblastose fetal. Hoje em dia o exame dos grupos sangüíneos tornou-se prática corrente em São Paulo e preciosas vidas são salvas graças ao conhecimento da herança desse fator genético. Como aumentam dia a dia os conhecimentos sobre novos tipos sangüíneos, esses estudos contribuirão decisivamente para esclarecer a constituição genética das várias raças humanas.

No setor referente à genética aplicada ao melhoramento do gado para corte, nota-se entre os técnicos do Departamento da Indústria Animal de São Paulo, grande entusiasmo pela constatação de diferenças acentuadas na capacidade de engorda das várias raças indianas, característico que se tem mostrado de 
boa hereditabilidade. Vários outros projetos de melhoramento de animais domésticos vêm sendo há longos anos, conduzidos pelos técnicos daquele Departamento.

\section{O Instituto Agronômico}

O outro centro de estudo de genética, devotado mais à aplicação da genética ao melhoramento de nossas principais plantas econômicas, se localiza no Instituto Agronômico de Campinas. Fundado em 1887, este estabelecimento, reconhecido como um dos mais completos do continente, vem de longa data, pondo em prática os métodos de melhoramento de plantas baseados em princípios mendelianos. Trabalhos de genética pura bem como de citologia vêm igualmente sendo realizado neste estabelecimento.

Já em 1927, por sugestão de Theodureto de Camargo, organizou-se no Instituto Agronômico uma seção de Genética com finalidades bastante amplas, como as de estudos de questôes de genética vegetal, criação de variedades, provas de plantas de valor econômico, etc. Para dirigir esta nova seção foi contratado o geneticista austríaco E. Taschdjian que realizou algumas observaçōes sobre o café, descrevendo vários mutantes encontrados.

Em 1932, C. A. Krug, passou a dirigir a Seção de Genética, organizando e dando início a planos para o melhoramento de várias de nossas principais plantas econômicas, principalmente para o café e milho.

Particularmente para o café, planta perene que tanta riqueza tem distribuído ao povo paulista, o plano de trabalhos organizados por Krug e J. E. T. Mendes, numa época em que quase nada mais se esperava desta cultura em São Paulo, é realmente extenso e completo, à altura do seu valor econômico.

Como era de se esperar, na execução desse extenso plano, Krug vem contando com numerosos colaboradores tanto na parte referente ao estudo botânico das variedades, como no que diz respeito à biologia da reprodução, análises genéticas e melhoramento.

Assim Krug, J. E. T. Mendes e A. Carvalho realizaram estudos botânicos e biométricos das variedades de café encontradas em São Paulo, tanto das que são cultivadas em larga escala como daquelas que apresentam limitado valor econômico. Diversas variedades novas foram encontradas no decorrer da 
execução desse plano, como caturra vermelho e amarelo, semperflorens, cera, etc., e várias outras se acham em observação. No que se refere à biologia da reprodução do café, Krug e A. Carvalho, baseados nos resultados obtidos com a variedade cera de $C$. arabica, chegaram à conclusão de que essa espécie é autofértil e que a quantidade de sementes formadas como resultado da autopolimização é cerca de dez vezes mais freqüente que as semente resultantes da fecundação cruzada. Estes dados podem ser considerados básicos para a escolha dos métodos de melhoramento, pois as demais espécies de café existentes em Campinas, como Coffea canephora, C. dewevrel, C. congensis e C. liberica são autoestéreis e se multiplicam por fecundação cruzada.

As análises genéticas dos mutantes de C. arabica vêm sendo realizadas em Campinas desde 1933. Embora demoradas e dispendiosas essas análises em execução por C. A. Krug, A. Carvalho e Hermínio Antunes Filho, vêm fornecendo bases seguras para os trabalhos de melhoramento.

Tomando a variedade typica como padrão tem-se demonstrado que a maioria dos mutantes, muitos deles já descritos como variedades distintas de C. arabica, diferem da variedade typica apenas por um a três pares de fatores genéticos principais. Vários desses mutantes se apresentam recessivos, outros com dominância incompleta e finalmente outros completamente dominantes em relação aos alelos encontrados na variedade typica. Tem-se igualmente verificado que vários dos fatores genéticos do café estudados apresentam efeito pleiotrópico acentuado, isto é, afetam vários órgãos da planta, como os fatores anomala, fasciata, maragogipe, etc., enquanto outros atuam apenas sobre determinados característicos como xanthocarpa, erecta, etc. Apesar de não se ter encontrado fatores ligados no cafeeiro, devido ao limitado número de fatores genéticos até agora analisados, observaram-se vários casos complexos de interação e epistasia entre alguns deles. Embora esses fatores no geral sejam bastante estáveis, tem-se notado instabilidade somática principalmente dos fatores nena e xanthocarpa.

Pelo cruzamento de vários mutantes com a variedade murta, vem-se obtendo alguns dados referentes à sua origem, isto é, se derivam da variedade typica ou bourbon.

Com referência às análises genéticas em outras espécies de Coffea, muito pouco se tem realizado em virtude do limitado valor econômico que essas espécies 
apresentam para nós e também por serem autoestéreis. Todavia alguns dados vêm sendo obtidos referentes aos fatores fasciata, nana e angustifolia de Coffea canephora, xanthocarpa de C. congensis e cor das flores em C. Dewevrel.

Numerosos cruzamentos interespecíficos são anualmente realizados a fim de se estudar os fatores genéticos conhecidos em Coffea arabica em combinação com os fatores genéticos de outras espécies de café. Vários tipos de variegação acham-se em estudo, sendo um deles transmissível apenas pela planta mãe. Convém salientar que as pesquisas relativas à genética do cafeeiro são quase que exclusivamente realizadas no Brasil, em Campinas, pois nenhum outro país cafeicultor da atualidade vem se dedicando a esses estudos.

As pesquisas de citologia do cafeeiro iniciadas por C. A. Krug e prosseguidas por A. J. T. Mendes, C. H. T. Mendes Conagin, Dixier M. Medina e O. Bacchi, têm contribuído para elucidar problemas relativos à taxonomia, genética e melhoramento do café. Assim, foi verificado que certos mutantes constituem formas poliplóides ou haplóides de $C$. arabica e devem ser considerados apenas como formas das variedades que ocorre. Algumas formas haplóides têm sido estudadas por A. J. T. Mendes tendo duplicado o número de cromossomos de uma delas pela colchicina, transformando-a de estéril em fértil e produtora de linha pura de café, de utilidade nos trabalhos de melhoramento. O desenvolvimento por esse mesmo autor de uma técnica especial para duplicar o número de cromossomos nos tecidos somáticos abriu novas possibilidades para os híbridos interespecíficos triplóides de Coffea e também para outras plantas que se multiplicam por via vegetativa. Uma forma hexaplóide de café, fértil, foi assim obtida, de bastante interesse para os trabalhos em andamento. Pesquisas sobre aneuplóides, especialmente monossomos, sobre partenogênese, partenocarpia, casos anormais de fertilização e sementes sem embriāo, por A. J. T. Mendes, sobre a morfologia dos cromossomos, meiose e formação dos gametas no café por A. J. T. Mendes, C. H. T. Mendes Conagin e D. M. Medina, sobre o desenvolvimento do endosperma e do fruto do café por A. J. T. Mendes e D. M. Medina, são problemas investigados e que têm direta relação com os trabalhos de genética e melhoramento ora em execução.

A autoesterilidade em C. canephora foi analisada por C. H.T. M. Conagin que também estudou o efeito do paradiclorobenzeno nos tecidos do café, a fim de tornar mais distintos os cromossomos em metáfase. 
A ocorrência da poliembrionia foi investigada por Krug, J. E. T. Mendes que constataram a ocorrência da verdadeira e falsa poliembrionia em café. Este mesmo assunto mereceu também atenção de A. J. T. Mendes, que analisou a poliembrionia com maiores detalhes.

Os trabalhos de melhoramento, com a finalidade de aumentar a produção de café por unidade de área, têm-se tornado bastante extensos, envolvendo a análise de produção individual de mais de 60.000 cafeeiros e dos característicos de suas sementes. No decorrer da realização desses trabalhos em Campinas e também nas estações experimentais do Instituto Agronômico em Ribeirão Preto, Pindorama, Mococa, Jaú e Monte Alegre do Sul, Krug vem tendo a colaboração de J. E. T. Mendes, A. Carvalho, H. Antunes Filho, Célio S. Novais Antunes, R. Kerr Nogueira, Aldo Alves, Djalma Foot, J. Aloisi Sobrinho, M. Vieira de Morais, W. Lazzarini, Sebastião Alves, T. R. Rocha, A. Junqueira Reis, além de todos os técnicos da Seção de Café do Instituto Agronômico e outros que atualmente não mais se dedicam a essas investigações.

Além do isolamento de centenas de progênies das principais variedades econômicas, são igualmente realizados cruzamentos entre plantas selecionadas da mesma variedade, de variedades diferentes e mesmo entre espécies distintas. As gerações avançadas desses híbridos são estudadas a fim de se isolarem recombinações possuidoras de característicos favoráveis encontrados em plantas diferentes. Como decorrência do estudo de gerações seguidas tem-se verificado que as variedades bourbon e typica não apresentam efeito desfavorável das autofecundações sucessivas e que os híbridos não apresentam heterose. Em plantas heterozigotas para o fator maragogipe, ao contrário, tem-se notado produção mais elevada do que nas homozigotas para esses alelos.

Uma série de observações vem sendo efetuada por C. M. Franco, a fim de verificar a ocorrência de resistência aos efeitos da baixa temperatura em diferentes formas de café. A geada ocorrida em 1953, em Campinas, permitiu a observação de possível resistência entre as diversas progênies dos ensaios experimentais por A. Carvalho, H. Antunes Filho e Aldo Alves.

Embora haja ampla possibilidade de seleção dentro das variedades de $C$. arabica, a Seção de Genética, em colaboração com M. Damy de Souza Santos do Departamento de Física da Universidade de São Paulo, vem desenvolven- 
do uma série de tratamentos de sementes de café com raios-X para obter mutações que possam ter interesse para as investigações em andamento.

As numerosas progênies de café que atualmente se acham em ensaios são derivadas de plantas matrizes que tiveram sua produção controlada por vários anos e de plantas diretamente escolhidas nos cafezais levando-se em conta um ano de alta produção apenas, além dos característicos vegetativos. Esses dois processos de seleção tem-se mostrado eficiente na escolha de plantas matrizes superiores. Análises também vêm sendo feitas a fim de se verificar a eficiência da escolha das melhores progênies após os seis primeiros anos de produção. Outras análises se relacionam com a relação entre a produção das plantas matrizes e a de suas progênies.

Os mais recentes ensaios de progênies de café, que encerram as melhores seleções de bourbon amarelo, mundo novo, bourbon vermelho e caturra, irão contribuir para melhor esclarecer a sua reação nas várias localidades onde são estudadas. Observações sobre a variabilidade da produção mensal de cafeeiros semperflorens, que floresce e frutifica quase que continuamente durante todo o ano, bem como dos tipos de fruto e semente produzidos, foram feitas por C. S. Novaes Antunes.

De todas as plantas estudadas as mais promissoras têm sido rapidamente multiplicadas em larga escala a fim de se obter quantidade maior de sementes que são entregues aos lavradores. Calcula-se que somente em 1953 foram plantadas cerca de 30 milhões de covas de cafeeiros, todos derivados de linhagens selecionadas no Instituto Agronômico. Considerando que o cafeeiro é planta perene e que cada um desses cafeeiros poderá produzir grande número de sementes nos próximos anos, é de se presumir que, embora a procura de sementes selecionadas de café seja atualmente intensa, logo mais todas as novas plantações poderão ser feitas exclusivamente com linhagens selecionadas. Não se torna necessário salientar o que essas linhagens representam para a economia do nosso Estado.

As pesquisas de genética e melhoramento do cafeeiro prosseguem em ritmo acelerado, procurando esclarecer o mecanismo hereditário dos novos mutantes e procurando novas estruturas genéticas mais favoráveis, isto é, vigorosas, produtivas e adaptadas aos vários tipos de solos e clima de São Paulo. O melhoramento do milho tem também merecido especial atenção 
do Instituto Agronômico, havendo Krug elaborado e dado início a um extenso plano a fim de isolar linhagens homogêneas a partir das variedades cultivadas entre nós.

Muitas outras variedades foram importadas dos países onde se cultiva o milho em larga escala e também dos prováveis centros de origem e diversificação desse cereal. Linhagens com elevado número de autofecundaçôes foram importadas, principalmente dos Estados Unidos, a fim de estudar o seu comportamento entre nós, verificando-se que quase todas elas se desenvolvem muito mal em nosso meio. A finalidade do isolamento dessas linhagens puras é a obtenção do milho híbrido pelo cruzamento entre elas. Graças a esse plantio de melhoramento, iniciado em 1932, São Paulo pode hoje se orgulhar de ser a segunda região do mundo, depois dos Estados Unidos, a contar com milho híbrido próprio, obtido de linhagens aqui isoladas.

As pesquisas sobre o milho híbrido, que já contou e vem contando com vários colaboradores, tais como, G. P. Viegas, L. Paolieri, E. Smith, M. P. Penteado e S. O. Pacitti, e hoje a cargo do primeiro deles, não cessam. Novos processos de melhoramento são estudados, centenas de autofecundações e cruzamentos são anualmente feitos, centenas de linhagens e novas combinações híbridas são experimentadas para se conseguir híbridos de mais alto rendimento. A produção comercial de sementes híbridas de milho, trabalho que requer bastante vigilância e organização, está em São Paulo, sob o controle do Instituto Agronômico e da Divisão de Fomento Agrícola, em cooperação com vários proprietários particulares.

O melhoramento do milho doce e o milho pipoca, até a pouco a cargo de M. J. Purchio, hoje vem sendo realizado por S. O. Pacitti, que vem estudando grande número de variedades e linhagens recém-introduzidas e efetuando numerosos cruzamentos, a fim de se obterem variedades mais adaptadas ao nosso meio. Não há dúvida de que o milho híbrido, exemplo típico da aplicação prática dos princípios de genética, constitui para São Paulo uma das glórias de sua agricultura.

Os vários tipos de sorgo, tanto para a produção de grãos, de massa verde como para fabricação de vassoura, vêm sendo estudados por G. P. Viegas, M. J. Purchio e Djalma Foot, para se isolarem linhagens sem os defeitos que algumas das atuais variedades apresentam. 
O papel desempenhado na economia de São Paulo pelas seleções de algodão efetuadas pelo Instituto Agronômico é deveras conhecido. Podem as fases desses estudos ser agrupadas em dois períodos a saber: antes e depois dos extensos trabalhos de R. Cruz Martins. Não houvesse esse técnico isolado linhagens altamente produtivas e de boa qualidade de fibras, não se poderia imaginar o que teria ocorrido a São Paulo com o abandono do café em 1929 e sem outra cultura rendosa para substituí-lo. O êxito dos lavradores no cultivo do algodão não se deve ao acaso, mas sim ao fato de todas as fases de cultivo terem sido investigadas no Instituto Agronômico, como também por contarem com sementes selecionadas em quantidades suficientes, produzidas em campos de cooperação, pela primeira vez instalados em São Paulo nessa ocasião. A seleção do algodoeiro posteriormente teve a colaboração do conhecido geneticista S. C. Harland que, além de organizar uma ampla coleção de variedades e espécies de algodão, introduziu técnicas das mais acuradas para instalação de ensaios experimentais e análise dos resultados obtidos. Numerosos outros trabalhos de hibridação e seleção do algodão foram e continuam a ser efetuados por I. Ramos, O. S. Neves e Popílio A. Cavaleri visando tipos mais aperfeiçoados, produtivos e de mais alta qualidade de fibras. Os altos rendimentos da seleção I. A. Campinas-817 ora plantada em larga escala no Estado, resultou dessas extensas e laboriosas pesquisas de campo e de laboratório, visando ao aprimoramento das qualidades agronômicas e tecnológicas do algodão. Resistência a moléstias de vírus do algodoeiro são estudadas por A. S. Costa, lançando mão da valiosa coleção de espécies e variedades cultivadas e selvagens, mantida pelo Instituto Agronômico, tendo isolado linhagens bem resistentes à ramulose. Algumas investigações foram feitas por A. J. T. Mendes, para verificar as possibilidades da duplicação do número de cromossomos pela colchicina de duas espécies de algodão, isto é, Gossypium hirsutum e G. herbaceum, usando várias técnicas de aplicação desse alcalóide.

Muitas recombinações genéticas derivadas das nossas principais variedades de cana-de-açúcar e de cruzamentos artificiais interespecíficos são anualmente estudadas por J. M. Aguirre Júnior, A. L. Segala, R. Alvarez, H. Correia de Arruda e S. Correia de Arruda, para verificação de sua resistência a moléstias de vírus e também quanto à riqueza em açúcar e demais qualidades agronômicas. $\mathrm{O}$ rápido e crescente desenvolvimento das áreas de cultivo da cana em São 
Paulo exige constantes trabalhos de melhoramento para que essa cultura seja mantida em bases cada vez mais econômicas.

Se bem que o Estado de São Paulo já conte com variedades de arroz bem adaptadas ao cultivo de sequeiro e com irrigação, trabalhos de hibridação realizados por E. B. Germeck, entre estas formas e demais variedades cultivadas em quase todas as outras regiōes rizícolas do mundo, têm permitido diversificar geneticamente o nosso material, a fim de se poder procurar novas recombinaçôes nas gerações que se seguem a esses cruzamentos. Seleção para manter as variedades comerciais são feitas por H. S. Miranda.

$\mathrm{O}$ amendoim, planta do continente americano, vem sendo ativamente estudado por O. Ferreira de Souza, V. Canécchio Filho, E. Abramides, C. H. T. Mendes Conagin e A. Conagin, procurando-se obter linhagens produtivas e ricas em óleo. Hibridações entre vários tipos de amendoim, processo deveras trabalhoso, vem sendo realizadas por C. H. T. M. Conagin, bem como estudos relativos à classificação das variedades de amendoim cultivadas. São realmente auspiciosos os resultados obtidos nestes últimos anos com o isolamento de variedades de amendoim mais adaptadas em São Paulo. Estudos citológicos básicos foram realizados por A. J. T. Mendes que determinou o número de cromossomos tanto para o amendoim cultivado, como para as espécies selvagens, verificando que as formas cultivadas possuem 40 cromossomos somáticos, enquanto as selvagens possuem 20.

Outra leguminosa de grande interesse econômico é a mamoneira, cujos estudos de melhoramento foram traçados e iniciados por C. A. Krug, P. T. Mendes e prosseguidas por V. Canécchio Filho e O. Ferreira de Souza. A variedade anã n. 38, hoje amplamente cultivada no Estado, embora não tenha sido obtida no Instituto Agronômico vem continuamente sendo selecionada, procurando-se linhagens mais produtivas, de maior rendimento em óleo e resistência a moléstias. Uma série grande de hibridações vem recentemente sendo efetuada por V. Canécchio Filho e A. Carvalho, a fim de diversificar geneticamente as linhagens anãs e possibilitar novas seleções, dentro desse tipo de mamoneira.

O plano de seleção de tungue também elaborado por C. A. Krug e P. T. Mendes, está sendo realizado por V. Canécchio Filho, em colaboração com V. Gonçalves de Oliveira e D. M. Correia, tendo-se encontrado progênies de alta produção de sementes e boa porcentagem de óleo. 
A soja é outra oleaginosa cujos estudos por N. Abdo Neme, J. Gomes da Silva e S. Miyasaka, visam a isolar linhagens produtivas, ricas em óleo e proteínas e resistentes aos nematóides produtores de galhas nas raízes. Muitas variedades são examinadas para se encontrar as fontes genéticas de resistência aos nematóides e também a moléstias, e diversas hibridações são feitas para se poder eliminar vários defeitos de algumas das atuais variedades em cultivo, como sementes rachadas, de cor escura etc.

O feijāo vem sendo objeto de investigações por L. A. Nucci, procurando primeiramente uniformizar as variedades comumente cultivadas e isolar linhagens com boas características de produção, e possível resistência às moléstias mais comuns e bom aspecto das sementes. Da sucessão de observações realizadas nas experiências, tornou-se possível a identificação de uma linhagem, não comercial, resistente à ferrugem, que foi posteriormente usada nas hibridações com as formas comerciais. Uma nova linhagem derivada dessas hibridações acha-se na fase de multiplicação para entrega aos lavradores, enquanto outras continuam ainda a ser observadas em experiências realizadas em algumas estações experimentais deste Instituto.

Com relação ao melhoramento da bananeira, J. Ferreira da Cunha vem efetuando alguns cruzamentos para conseguir formas resistentes a moléstias e de valor comercial. Esse mesmo técnico efetuou várias hibridações entre espécies de baunilha para verificar a compatibilidade e aumentar a produção e dimensões dos frutos.

Híbridos artificiais entre várias espécies de abacaxi existentes na coleção do Instituto Agronômico, estão sendo observados por O. Galli com o objetivo de eliminar os espinhos e melhorar a qualidade das variedades ora em cultivo em São Paulo.

Os trabalhos de melhoramento da laranja Baianinha, a cargo de S. Moreira, F. G. Brieger e C. Roessing, visam isolar clones produtivos, de frutos pequenos e da melhor qualidade. Vários híbridos foram feitos e se acham em observação entre a laranja Baianinha e outras variedades, a fim de transmitir à Baianinha fatores para maior resistência e melhor textura. Vários híbridos artificiais, tanto intra como interespecíficos estão sendo estudados para se ter dados sobre a transmissão dos característicos das várias formas de Citrus. A ocorrência da poliembrionia dificulta bastante essas análises genéticas, que se tornam muito 
dispendiosas. Pesquisas referentes a mutações somáticas em limão doce foram feitas por I. Dias de Toledo, as quais vieram explicar a ocorrência de frutos ácidos em ramos de limão doce.

Estudos detalhados de quimeras citológicas periclinais foram feitos por Krug e H. B. Frost esclarecendo, em parte, o papel que as diferentes camadas tomam na formação dos tecidos da folha e da haste em Citrus. O número de cromossomos de várias espécies de Citrus foi determinado por Krug e Oswaldo Bachi; este também efetuou estudos sobre a esterilidade do limão Tahiti, sobre a megasporogênese, a fertilização, a poliembrionia em Citrus e a relação entre a poliploidia e tamanho dos estomas.

Com relação ao melhoramento do trigo, centenas de introduções de variedades de todos os países que o cultivam foram estudadas por C. A. Krug, G. P. Viegas, L. Paolieri, M. J. Purchio e Milton Alcover, para se isolar linhagens adaptadas às nossas condiçôes. Mais recentemente $\mathrm{M}$. Alcover vem desenvolvendo um plano extenso de hibridações entre várias formas de trigo resistentes às ferrugens e à seca, a fim de conseguir novas recombinaçôes genéticas de maiores possibilidades.

O melhoramento de grande número de espécies hortícolas está sendo realizado por O. Toledo Prado, visando qualidade e alta produção. As variedades de abóboras isoladas e atualmente em distribuição são bastante homogêneas e de boas qualidades de armazenamento. Linhagens de couve-flor e de repolho que, além das qualidades exigidas pelo mercado consumidor, também produzem grande quantidade de sementes, bem como novas linhagens de cenoura e morangueiro foram obtidas por L. de Souza Camargo, que já as vem distribuindo aos lavradores do Estado. Linhagens de alface estão sendo estudadas por S. Alves e J. Botter Bernardi, visando produtividade e possibilidade de cultivo de verão.

O feijão de vagem é objeto de investigação por J. B. Bernardi a fim de isolar linhagens de porte alto, para produção de vagem de pouca fibra e sem fio, do tipo manteiga.

Híbridos entre as principais variedades de pessegueiro já aqui adaptadas com variedades de recente introdução, foram conseguidas por O. Regitano, alguns dos quais considerados de alta qualidade e que poderão ser multiplicados em larga escala por via assexuada. Híbridos entre diferentes tipos de 
caquizeiro foram também obtidos por Regitano procurando-se selecionar tipos produtivos e de menor conteúdo de tanino.

A importância da cultura da videira em nosso Estado cresce dia a dia, requerendo novos tipos resistentes a moléstias, destinados tanto ao consumo de mesa, como para o fabrico de vinho e de suco de uva. J. R. A. Santos Neto, vem realizando numerosas hibridaçôes e seleção entre vários tipos de uva, tendo já obtido alguns híbridos precoces, resistentes a moléstias e destinados a esses vários fins. Esses híbridos têm-se mostrado bem adaptados às nossas condiçôes de verão úmido, o que representa um grande avanço para a viticultura paulista. Híbridos de uva sem sementes e destinados ao consumo de mesa também já foram obtidos por J. R. A. Santos Neto. J. S. Inglês de Souza vem efetuando observaçôes sobre vários mutantes somáticos derivados da variedade Niágara Branca, alguns de bastante interesse do ponto de vista genético e comercial. W. Correia Ribas vem também efetuando cruzamentos artificiais e observações sobre os híbridos obtidos.

O tomateiro, uma das espécies mais bem conhecidas do ponto de vista genético, tem, atualmente, bastante interesse econômico para São Paulo. No seu melhoramento A. S. Costa e O. T. Prado têm levado em conta, além da produção e tipo do fruto, principalmente resistência a moléstia e tipo adequado de crescimento da planta, para o que se tem tornado necessário transferir às variedades comerciais comuns, fatores genéticos encontrados em outras espécies selvagens ou em diferentes variedades do tomateiro. A herança de um fator genético que determina ocorrência de manchas nas folhas de tomateiro, semelhantes às causadas por vírus, foi analisado por A. S. Costa.

Apesar de São Paulo já possuir variedades de mandioca de alto rendimento, E. S. Normanha e A. S. Pereira vêm efetuando autofecundações e cruzamentos artificiais nas variedades de interesse econômico como Branca de Santa Catarina e outras para conseguir tipos resistentes à bacteriose e também de alto rendimento. Cruzamentos entre diferentes espécies de Manihot estão sendo iniciados, a fim de se obterem informaçôes sobre o grau de seu isolamento.

O. J. Boock vem analisando centenas de mudas obtidas de sementes autofecundadas e obtidas pela hibridação artificial de batatinha à procura de novos clones, resistentes a moléstias e adaptadas às nossas condições, pois as variedades que ora se cultivam em São Paulo são todas oriundas de outros 
países. Tais trabalhos haviam sido iniciados anteriormente por Krug e L. A. Nucci. Observações sobre o comportamento de numerosas variedades estrangeiras de batatinha são anualmente efetuadas por Boock em várias regiōes do Estado e em diferentes épocas do ano.

Estudos sobre mutações somáticas ocorridas nas variedades comerciais de batata doce, e sobre numerosas plantas obtidas de sementes de variedades comerciais foram realizados por A. Paes de Camargo e L. A. Nucci. Alguns mutantes se têm mostrado iguais ou mesmo superiores aos melhores clones em multiplicação. Entre as plantas obtidas de sementes, por A. P. de Camargo, que no geral se mostram extremamente variáveis, foram encontradas algumas com raízes não tuberosas, de bastante interesse do ponto de vista evolutivo. Convém salientar que nas plantas que se multiplicam por via vegetativa, encontradas as combinaçõos favoráveis, embora altamente heterozigotas, elas podem ser multiplicadas em larga escala, constituindo clones diretamente aproveitáveis pelos lavradores.

O desenvolvimento de um novo clone de menta por A. Rodrigues Lima, como produto de segregação de plantas de menta comum, resistente à ferrugem, e produtor de um óleo de tipo especial, veio permitir a sobrevivência dessa cultura em São Paulo, devido ao seu mais alto rendimento em comparação com as demais variedades comerciais. Várias linhagens oriundas de plantas selecionadas ou de hibridações entre variedades de fumo foram isoladas por A. Rodrigues Lima, S. Ribeiro dos Santos e R. Forster, apropriadas para indústria de fumo em corda, capas de charutos, e para cigarros. Clones de capim cidreira, obtidos por A. Rodrigues Lima e A. Jacob com elevada riqueza de óleo essencial, a partir de plantas altamente heterozigotas, têm-se mostrado bastante promissores, bem como clones de piretro de elevado teor em princípios ativos.

Na propagação sexual de Agave sisalana, J. C. Medina verificou que milhares de seedlings obtidos, nenhum apresentou folhas com bordos desprovidos de espinhos, embora as plantas originais não apresentem esses espinhos. Atualmente o Instituto Agronômico possui uma das mais completas coleções de espécies do gênero Agave, as quais vêm sendo observadas quanto aos seus característicos de produção de fibras e utilizadas eventualmente em trabalhos de cruzamentos. Estudam-se, no momento, os híbridos provenientes do cruzamento de $A$. sisalana ou sisal, com $A$. fourcroydes ou henequem, do México. 
Estão sendo observadas, quanto à produção e característicos das fibras diversas variedades de rami, por J. C. Medina e G. de Paiva Castro.

Observaçôes relativas a várias plantas ornamentais vêm sendo feitas por $\mathrm{H}$. Moreira de Souza e G. C. da Silva, principalmente com gloxinias procurando obter linhagens de haste ereta, e de maior número de lobos na corola, e ciclames para obter sementes em nossas condições e estudo da variabilidade.

A separação de estirpes de levedo para fermentação do caldo de cana da variedade Co. 290, que é a mais difundida no Estado e que mostra certa dificuldade de fermentação, vem sendo efetuada por Cyro G. Teixeira no Laboratório de Microbiologia. Seleções de estirpes de Rhizobium estão sendo feitas para inoculações de sementes de feijão comum, soja, e várias outras leguminosas usadas como adubo verde.

A análise genética da herança da forma melânica em Dysdercus mendesi foi realizada por L. O. Teixeira Mendes que, também, fez estudos sobre a meiose e sobre ocorrência de interpretação de cadeias de cromossomos formadas no tecido somático desse inseto.

Em 1941, o grande agrônomo Edmundo Navarro de Andrade, após receber a Medalha Meyer, a mais alta condecoração concedida àqueles que realmente souberam prestar serviços à coletividade pela introdução e aclimatação de espécies vegetais, solicitou a colaboração de C. A. Krug para elaborar e dar início em Rio Claro, sob o patrocínio da Companhia Paulista de Estradas de Ferro, a um plano de melhoramento das espécies de eucaliptos. Deste plano constaram estudos de taxonomia das espécies de eucaliptos, biologia da reprodução, determinação do número de cromossomos e estudo de numerosas progênies de plantas matrizes selecionadas. Estes trabalhos realizados em colaboração com Asdrúbal Silveira e A. Navarro Sampaio vieram suprir dados básicos para o prosseguimento do plano de melhoramento dessa preciosa essência florestal.

\section{Conclusão}

O panorama do desenvolvimento da genética nestes últimos vinte anos em São Paulo, aqui apresentado resumidamente e talvez, com algumas falhas involuntárias, não deixa de ser animador. O que há de mais significativo é que as perspectivas de investigações neste campo da biologia somente tenderão a 
progredir no futuro pois muitos dos atuais pesquisadores são os próprios professores e assistentes da Universidade de São Paulo, que certamente irão incutir no espírito dos alunos o devotamento pelas pesquisas científicas tão necessárias às grandes realizações no campo da biologia, no que São Paulo se tem mostrado pioneiro dentro do Brasil.

Outro acontecimento de relevo que se tem observado é que vários investigadores que tiveram sua formação em São Paulo, estão hoje divulgando e aplicando seus conhecimentos em escolas e institutos de outras Unidades da Federação.

Convém salientar que o impulso que a Genética vem tomando em São Paulo deve-se em parte ao governo que, compreendendo a importância destes estudos, tem permitido o comissionamento de técnicos para efetuar estágios e tomar cursos sobre genética, principalmente nas universidades norte-americanas e contribuindo para que nossas instituiçôes recebam técnicos como Th. Dobzhansky e M. M. Rhoades, considerados entre as maiores autoridades no assunto, para colaborarem com os nossos especialistas nos trabalhos aqui em execução. Também as fundaçōes Rockefeller e Guggenheim têm prestado inestimável apoio a São Paulo, concedendo bolsas de estudo a muitos dos que hoje se dedicam a trabalhos de genética entre nós e auxiliando com aparelhos e material de laboratório para que as pesquisas progridam sem interrupçôes.

Constituindo os estudos de vários ramos da genética a pedra angular de toda a pesquisa biológica da atualidade, é de se esperar que os laboratórios de genética de São Paulo venham a se multiplicar no futuro, influindo decisivamente no progresso geral das ciências biológicas no País. 